\title{
Combining Transposon Mutagenesis and Reporter Genes to Identify Novel Regulators of the Topa Promoter in Streptomyces
}

Martyna Gongerowska-Jac ( $\square$ martyna.gongerowska-jac@uwr.edu.pl )

University of Wroclaw: Uniwersytet Wroclawski https://orcid.org/0000-0002-3395-6610

Marcin Jan Szafran

University of Wroclaw: Uniwersytet Wroclawski

Dagmara Jakimowicz

University of Wroclaw: Uniwersytet Wroclawski

\section{Research Article}

Keywords: Streptomyces, transcription regulation, lux reporter gene, transposon mutagenesis, TopA

Posted Date: March 18th, 2021

DOl: https://doi.org/10.21203/rs.3.rs-321607/v1

License: (c) (i) This work is licensed under a Creative Commons Attribution 4.0 International License.

Read Full License 


\section{Abstract}

\section{Background}

Identifying the regulatory factors that control transcriptional activity is a major challenge of gene expression studies. Here, we describe the application of a novel approach for in vivo identification of regulatory proteins that may directly or indirectly control the transcription of a promoter of interest.

Results

A method based on the combination of Tn 5 minitransposon-driven random mutagenesis and lux reporter genes was applied for the first time for the Streptomyces genus. As a proof of concept, we studied the top $A$ supercoiling-sensitive promoter, whose activity is dependent on unknown regulatory factors. We found that the sco4804 gene product positively influences topA transcription in S. coelicolor, demonstrating SCO4804 as a novel player in the control of chromosome topology in these bacteria.

\section{Conclusions}

Our approach allows the identification of novel Streptomyces regulators that may be critical for the regulation of gene expression in these antibiotic-producing bacteria.

\section{Background}

Prokaryotic gene expression is a process that is adjusted to the growth phase and to the changes in environmental conditions. As bacterial gene expression is predominantly regulated at the transcriptional level, bacterial genomes encode numerous proteins that control transcription initiation. Among them, the key players are DNA-binding proteins such as sigma factors, which determine promoter recognition by RNA polymerase (RNAP), as well as other transcription factors (TFs), acting as repressors or activators, which may affect the binding of RNAP to a promoter (Lloyd et al, 2001; Browning and Busby, 2016). However, non-DNA binding proteins such as anti-sigma factors, proteases and other proteins can also control the accessibility of direct regulators to the DNA, thus acting indirectly and playing a critical role in transcriptional regulation. Therefore, the identification of all the components of a regulatory system is a challenging task.

Most often, studies on the regulation of gene expression have been limited to searching for promoters bound and controlled by certain regulatory proteins (Bush et al., 2019; Huang et al., 2019). To date, several powerful methods for the determination of the DNA-binding sites of known TFs and the genes regulated by them have been developed, such as SELEX, ChIP-chip, ChIP-seq and RNA-seq (Bouvet 2001; Meng et al., 2005; Wu et al., 2006; Johannes et al., 2010; Hrdlickova et al., 2017). All these tools aim to identify all the putative targets of a certain regulatory protein (Baptist et al, 2013). However, on the other hand, there are only limited strategies to identify TFs of a given promoter of interest (Wang et al, 2015). Currently available techniques to identify TFs that bind specific regions include a modified bacterial one- 
hybrid reporter system (Guo et al., 2009) and in vitro DNA capture strategies (Park et al., 2005; Park et al., 2009; Burda et al., 2014; Truong-Bolduc and Hooper, 2018). To search for gene expression regulators in vivo, the combination of random transposon mutagenesis with reporter genes (predominantly lacZ or antibiotic resistance cassettes) was successfully developed. This strategy has been applied in a number of bacterial species (Pseudomonas chlororaphis, Proteus mirabilis, Staphylococcus aureus and Vibrio cholerae) (Luo et al., 2018; Szostek and Rather 2013; Burda et al. 2014, McDonough et al., 2014). Such approaches may be highly beneficial for the identification of global regulatory factors and the dissection of complex regulatory networks, such as those controlling secondary metabolite synthesis in Streptomyces.

Streptomyces are soil-dwelling bacteria that undergo morphological differentiation, which encompasses vegetative growth and sporulation (Flärdh and Buttner, 2009). They are used as producers of numerous biologically active secondary metabolites, such as antibiotics (approximately $60 \%$ of the world's natural antibiotics are Streptomyces-obtained), immunosuppressants and cytostatics (Chater, 2006). The pathways for the synthesis of secondary metabolites are encoded by gene clusters that are activated only at specific growth phases or physiological conditions (Gehrke et al., 2019; Szafran et al., 2020). Thus, the production of secondary metabolites is tightly controlled by complex regulatory systems, many of which remain uncharacterized. In silico predictions revealed that the genome of any Streptomyces species may encode up to 1100 transcriptional regulators (Romero-Rodriguez et al. 2015), a large fraction of which fall into one of the two main clades: pathway-specific regulators (PSRs) and pleiotropic/global regulators (McLean et al., 2019; Xia et al., 2020). PSRs are regulatory proteins (such as Actll-orf4, RedD and CdaR or TetR, Lacl, MerR, and LuxR family regulators (Wilson et al., 2001; Kuscer et al., 2007; Chater 2016; Wei et al., 2018; McLean et al., 2019; Xia et al., 2020, Nett et al., 2009)) that are usually situated in secondary metabolite biosynthetic gene clusters and directly control the expression of their nearby genes, while pleiotropic regulators (e.g, AdpA (Yamazaki et al., 2004; Wolański et al., 2011), AfsR (Hong et al., 1991; Floriano and Bibb, 1996), BldD (den Hengst et al., 2010), and DasR (Hillerich and Westpheling, 2006)) are scattered throughout the chromosome and positioned distantly from the genes they regulate. While the identification of PSRs is relatively straightforward, the identification of global regulators that control a particular gene of interest may be challenging. A deep understanding of all aspects of Streptomyces gene expression, particularly transcription, is crucial to better exploit these bacteria as producers of widely used compounds.

Notably, in Streptomyces, similar to other studied bacteria (Streptococcus pneumoniae, Haemophilus influenzae, Escherichia coli, Salmonella enterica), DNA supercoiling also plays a role in global gene regulation by directly affecting the transcriptional activity of a number of promoters (Gmuender et al., 2001; Rui and Tse-Dinh, 2003; Peter et al., 2004; Dorman and Corcoran, 2009; Ferrándiz et al., 2014; Webber et al., 2013; Szafran et al., 2019). In Streptomyces, chromosome supercoiling is a global regulatory factor that controls the transcription of $3-7 \%$ of genes (Szafran et al., 2019). Proper DNA supercoiling in the cell is controlled by a set of enzymes called topoisomerases. The opposing activities of topoisomerase I (TopA), which removes negative supercoils, and gyrase, which can introduce negative supercoils, maintain topological homeostasis in bacterial cells (Champoux, 2001). Inhibition of 
topoisomerase activity or alteration of their level leads to changes in chromosome topology and affects DNA transactions, including replication and transcription. One of the most important mechanisms that maintains the balance of topoisomerases activity is transcriptional control of their cellular level (Menzel and Gellert, 1983; Tse-Dinh, 1985). In contrast to many model bacterial species, TopA is the only type I topoisomerase in $S$. coelicolor; thus, it is essential and must be precisely regulated to maintain the proper level of chromosomal supercoiling (Szafran et al., 2016). TopA depletion in Streptomyces causes severe growth retardation, including increased DNA supercoiling and altered gene expression, including the expression of secondary metabolite genes (Szafran et al., 2013; Donczew et al., 2016). As in other bacteria, in $S$. coelicolor, the TopA level is predominantly regulated by the transcriptional control of the topA gene (Tse-Dinh, 1985; Ferrandiz et al., 2014; Ahmed et al., 2016; Szafran et al., 2016). In S. coelicolor, transcription of topA is driven from at least two promoters, with equal contributions of both promoters during both vegetative growth and spore production. The $p 1$ promoter was shown to be supercoiling sensitive, which corroborates the shortened distance between motifs - 10 and - 35 (Szafran et al., 2016). On the other hand, the comparison of the $p 2$ promoter to other known promoter sequences did not identify the known recognition site for sigma factors or other transcriptional regulators. Moreover, apart from transcriptional regulation, no other mechanism regulating TopA activity has been described in Streptomyces.

Here, to identify regulators of the topA promoter in S. coelicolor, we used an approach based on Tn5 minitransposon (mini-Tn5)-driven random transposon mutagenesis combined with the lux reporter system. As a proof of concept, we demonstrated that disruption of the sco4804 gene lowers the TopA level, while its overexpression results in enhanced topA promoter activity. We infer that $\mathrm{SCO} 4804$ is an indirect and pleiotropic regulator, which influences top $A$ and gyrase gene transcription. Thus, our approach allowed us to identify a new component of the chromosome supercoiling-related regulatory network in S. coelicolor.

\section{Results}

Application of transposon mutagenesis combined with the lux reporter gene system identifies potential regulators of topA promoter activity

Our previous studies have shown that $S$. coelicolor topA promoter activity is highly dependent on chromosome supercoiling, but neither negative nor positive protein regulators of the topA promoter have been identified (Szafran et al., 2016). Previously, to detect topA activity changes, we used a lux reporter

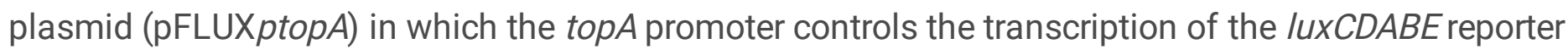
genes (Szafran et al., 2016). The luxCDABE operon encompasses the luxAB genes that encode luciferase (a heterodimer of LuxA and LuxB) and the luxCDE genes that encode enzymes necessary for luciferase substrate (tetradecanal) biosynthesis (Craney et al., 2006). Here, to search for unknown regulators of topA promoter activity, we combined lux reporter genes and random transposon mutagenesis. 
The S. coelicolor WT-lux strain (pFLUXptopA in the wild-type background) was subjected to random transposon mutagenesis (Fig. 1, stage 1), performed using a transposon plasmid (pHL734) containing the mini-Tn-5 transposon (Xu et al., 2017). pHL734 harbours a codon-optimized, highly efficient Tn5 transposase (under the control of the ermE promoter), which inserts mini-Tn-5 transposons randomly along the chromosome. The conjugation was repeated 4 times to deliver a WT-lux-tn library consisting of at least 8300 single colonies (Fig. 1, stage 2). Since transposition with mini-Tn5 occurs once per genome (as pHL734 cannot replicate in Streptomyces), each of the 8300 obtained colonies was assumed to carry a single transposon insertion in the genome. The luminescence of all obtained single colonies was measured during their growth on plates (Fig. 1, stage 3). Next, clones with altered luminescence intensity compared to the paternal WT-lux strain were selected ( 23 colonies with decreased luminescence and 18 colonies with increased luminescence) and re-streaked on fresh MS plates, and their altered luminescence in comparison to the paternal strain was verified (Fig. 1, stage 4). Subsequently, the clones were cultured in liquid medium, and the luminescence of selected clones was measured again (Fig. 1, stage 5). After the second round of selection, we obtained 12 colonies with significantly lowered or abolished luminescence signals and 2 colonies exhibiting elevated luminescence intensity. The presence of intact lux genes in clones with diminished fluorescence was confirmed by PCR (Fig. S1). Since modification of topA promoter activity detected by changes in lux gene activity was also expected to affect the TopA protein level (although earlier we observed that high activity of the topA promoter may not lead to high protein level; Szafran et al., 2016), we next aimed to estimate the TopA level in 14 transposant clones. To this end, the selected clones were cultivated in liquid, and the TopA level in the cell lysate was detected using Western blotting with anti-TopA antibodies and compared to the wild-type strain (Fig. 1, stage 6). Lower TopA protein levels (in comparison to those in the wild type strain) were observed in 2 clones, but we did not observe a significant increase in TopA protein levels in any of the mutants with elevated luminescence levels. Mutants with altered TopA protein levels were used for further analysis.

In summary, among the transposon mutants, we detected clones with both increased and decreased reporter gene activity. This indicates that the application of transposon libraries in combination with /ux reporter genes may be used to identify both positive and negative transcriptional regulators.

\section{Transposon mutation leads to modified transcription of the topA gene but does not affect chromosome supercoiling}

One of the WT-lux strain transposants, named lux-tn66, emitted very weak luminescence when cultured on solid and in liquid media (Fig. 2A and 2B). Western blot analyses showed that the level of TopA protein in lux-tn66 was approximately $50 \%$ of the protein level in the wild-type strain (Fig. $2 \mathrm{C}$, left), which was also verified by the measurement of topA transcript levels (Fig. 2C, right). RT-qPCR showed that the topA transcript level was approximately $70 \%$ of the topA transcript level in the wild-type strain. The observed discrepancy between the very low luminescence (indicating a very low level of topA promoter controlling reporter gene activity) and moderate lowering of the top $A$ transcript level and protein level suggests the 
complex regulation of the TopA protein level. However, the modified level of the topA transcript and its protein product confirmed the analysis of the reporter gene activity.

Based on our earlier studies, which showed that lowering the TopA protein level slows the growth of $S$. coelicolor in liquid and solid medium (Szafran et al. 2013), we measured the rate of growth of the luxtn66 strain. The growth rate analysis in liquid culture showed a slight retardation of transposon strain growth compared to the WT-lux paternal strain, but the growth rate of the transposon strain was still significantly faster than that of the TopA-depleted strain (in which the TopA protein level was approximately 20-fold lower than the wild-type TopA level (Szafran et al., 2013)) (Fig. 2D).

Since the severe TopA depletion increases chromosome supercoiling (Szafran et al., 2013), we checked whether decreased TopA protein levels in the transposon lux-tn66 strain caused any changes in global DNA supercoiling. To this end, we determined the level of global DNA supercoiling using modified strains containing the reporter plasmids pWHM3Hyg or pWHM3Spec. We compared the supercoiling of plasmids isolated from modified lux-tn66 (lux-tn66-RP), the wild-type strain derivative (MS10) and the TopAdepleted strain derivative (MS11), which was used as a positive control. DNA supercoiling in transposon mutant lux-tn66-RP was found to be unaffected by decreased TopA protein level (Fig. 2E). Since chromosome supercoiling is maintained by concerted action of gyrase and TopA, we expected that unaltered DNA supercoiling despite lowered TopA protein level in the lux-tn66 strain may result from changes in gyrase protein level. To test this hypothesis, we determined the activity of the $g y r B$ gene encoding one of the gyrase subunits. RT-qPCR analysis of the gyrB transcript level in the lux-tn66 transposon mutant showed significantly lower transcription level than wild-type gyrB transcription (Fig. 2F). This observation suggests that the lowered gyrase protein level compensated for the undesirable supercoiling changes triggered by the lowered TopA protein level in the lux-tn66 transposon mutant.

Based on our experiments, we infer that the modified level of topA gene transcription may either be linked to inactivation of the direct regulator of top $A$ gene expression or to the indirect regulation of top $A$ involving changes in the gyrase protein level in the mutant strain.

\section{SCO4804 is a potential candidate for a topA promoter activator/regulator}

Analysis of the transposon insertion site in the lux-tn66 strain (performed as described by Xu et al., 2017) showed that transposition occurred within the sco4804 gene, 85 bp downstream of its predicted start codon (Fig. 3A). The sco4804 gene encodes a hypothetical protein, SC04804, composed of 815 amino acids (predicted molar mass $86.04 \mathrm{kDa}$ ), that is rich in glycine and proline residues, and that is conserved in Streptomyces species. Structural prediction was performed using Robetta software (Raman et al., 2009) and indicated the presence of putative alpha-helical structures in the central region of the protein and unstructured regions at both the $\mathrm{C}$ - and $\mathrm{N}$-termini. Another analysis performed using PredictProtein (Yachdav et al., 2014), also showed three possible DNA-binding regions within the SCO4804 protein structure, which indicates that this protein may act as a transcriptional regulator (Fig. S2). Comparative analysis in the HOGENOM database (Penel et al., 2009) showed only a few homologues in other bacterial 
families (such as Alphaproteobacteria, Bacteroidetes and Cyanobacteria); however, no annotated role was provided for the protein in any species.

Positioning of the sco4804 gene (103 bp and $171 \mathrm{bp}$ of non-coding regions upstream and downstream of the sco4804 gene, respectively) suggests that it may not form an operon with adjacent genes; however, its genomic location is conserved within the Streptomyces genus. RNA-seq experiments performed previously using S. coelicolor wild-type and TopA-depleted strains (Szafran et al., 2019) showed significant, 8-fold induction of the sco4804 gene, as well as adjacent genes, under TopA-depleted conditions. This result was confirmed by RT-qPCR experiments using the WT-lux strain (MG03) and TopAdepleted lux strain (MG04) (Fig. 3B). This strongly suggests that sco4804 transcription is supercoilingdependent, corroborating its potential function in controlling topoisomerase levels.

\section{SC04804 overproduction increases topA promoter activity}

Since sco4804 transcription was shown to be induced by TopA protein depletion and disruption of the $s c 04804$ gene lowered TopA protein level, we predicted that SCO4804 acts as a positive regulator of topA transcription. To confirm this hypothesis, we constructed a strain overexpressing the sco4804 gene in the WT-lux strain background.

In the obtained strain (MG66), sco4804 (as a second gene copy in the integrative vector plJ6902) was controlled by a thiostrepton-inducible tipA promoter. Overexpression of sco4804 in MG66 cells was confirmed by RT-qPCR, revealing significantly elevated sco4804 transcript levels in comparison to the WTlux strain background (Fig. 4A). Having confirmed the induction of SC04804 in the MG66 strain, we set out to analyse the influence of SCO4804 on growth and topA promoter activity, as well as DNA supercoiling. Induction of SCO4804 led to slight retardation of growth compared to the control WT strain (with plJ6902 empty vector) (Fig. 4B). The topA promoter activity, measured using the lux reporter genes, was significantly increased by $5 c 04804$ induction either in 24-hour liquid or 48-hour plate cultures of the MG66 strain cultured in the presence of inducer ( $10 \mu \mathrm{g} / \mathrm{ml}$ thiostrepton) (Fig. $4 \mathrm{C}$ and D). This result indicated that overexpression of sco4804 caused significant activation of the topA promoter.

Next, to confirm that $s c 04804$ is a positive regulator of the topA promoter, we performed RT-qPCR analysis of topA transcript level in the MG66 strain with induced sco4804 overexpression. The results showed that increased topA transcript level was observed immediately after induction of sco4804 (30 minutes after the addition of thiostrepton to the medium), but after 60 minutes of incubation in the presence of inducer, topA transcript level decreased to the wild-type level (Fig. 4E). The discrepancy between long-term elevated lux activity after sco4804 induction and topA transcript elevation only during a very short period of time after induction suggests other post-transcriptional regulation modifications of topA transcript level, reinforcing our previous experiments (Szafran et al., 2019). Interestingly, the level of gyrB transcript exhibited similar changes, with an increase 30 minutes after SCO4804 induction and a decrease 60 minutes after induction (Fig. 4F). This indicates that the balance between gyrase and TopA activity was established and that the native supercoiling level could be restored. Indeed, the analysis of 
the reporter plasmid supercoiling showed no changes in the MG66 strain upon SC04804 induction (Fig. S3).

To check whether SCO4804 is a direct regulator of topA promoter activity, we tested its binding to the topA promoter in vitro. To this end, we purified the 6 His-SCO4804 protein using the E. coli BL21 (DE3) groEL-groES strain (Goloubinoff et al., 1989) (Supplementary info, Fig. S4A) and performed an electrophoretic mobility shift assay (EMSA) using a 458 bp DNA fragment encompassing the topA promoter and $632 \mathrm{bp}$ promoter of the $s c 04697$ gene, as well as $654 \mathrm{bp}$ of a part of the $s c 03928$ gene as the negative controls. While $6 \mathrm{His}-\mathrm{SCO} 4804$ bound all tested DNA fragments at a concentration of $1 \mu \mathrm{M}$, it was non-specific towards the topA promoter (Fig. S4B). Moreover, the addition of poly(dIdC) competitor DNA eliminated all non-specific interactions. A further pull-down assay and topoisomerase activity tests in the presence of $6 \mathrm{His}-\mathrm{SCO} 4804$ excluded the possibility of a direct interaction between SCO4804 and TopA (Figs. S5 and S6). These experiments suggest that SCO4804 influences topA promoter activity in an indirect manner.

\section{Discussion}

Our approach combining lux reporter genes and a random transposon library allowed us to perform highthroughput screening for potential regulatory proteins that control TopA protein level in S. coelicolor. Genome-wide transposition, as a powerful genetic tool, is widely used for systematic genetic studies of different bacterial species, including the construction of random insertion Streptomyces mutants with IS6100, Tn4560, IS493, Tn5, and Himar1 transposons (McHenney and Baltz 1996; Volff and Altenbuchner 1997; Weaden and Dyson 1998; Widenbrant and Kao 2007; Bilyk et al. 2013). The Tn5 minitransposon together with the codon-optimized Tn5 transposase displays high efficiency, less codon bias and lower host specificity than other transposases (Xu et al., 2017). In Streptomyces, random mutagenesis has previously been used to find repressors or activators of genes of interest, the products of which are easy to monitor within the cell, such as antibiotic or pigment production. This technique has been successfully applied for the identification of actinorhodin and landomycin E negative regulators (Chen et al., 2012; Horbal et al., 2013). Moreover, transposon mutagenesis combined with a reporter system based on an antibiotic resistance cassette was previously applied to search for repressors for daptomycin production in S. roseosporus (Luo et al., 2018a). However, this approach, based on antibiotic resistance genes, limited the screening to negative transcriptional regulators. The advantage of our approach, in comparison to the abovementioned approaches, is its suitability for high-throughput searches of both negative and positive regulators in Streptomyces transposon libraries. An approach similar to our approach and based on the combination of random mutant library construction and the lux reporter gene has been successfully applied for the identification of regulatory proteins of lecA in Pseudomonas aeruginosa (Diggle et al., 2002) and the acs gene in E. coli (Baptist et al., 2013). As our screen combines a mutant library with luciferase reporter constructs, the changes in gene of interest expression can be readily monitored in both liquid and solid cultures over time in different environmental conditions, which also enables the identification of regulators active only in particular environmental conditions. However, it must be considered that this method is limited to non-essential regulators. The other disadvantage of 
using lux reporter genes is the formation of artefacts due to metabolic influences on luciferase activity, but this can be overcome by using a second reporter system, for example, based on $g f p$ expression (Baptist et al, 2013). Nevertheless, because of the compatibility of all genetic elements, we believe that the strategy tested here for the identification of regulators may be widely used in Streptomyces.

By applying our screening approach, we expected to find any proteins that influence TopA protein level with either transcriptional or translational/post-translational modes of action. It was shown earlier that the topA promoter was activated by increased chromosome supercoiling and was inhibited due to chromosome relaxation after novobiocin treatment (Szafran et al., 2016). In addition to supercoiling sensitivity, no other factor controlling promoter activity has been identified to date; thus, the identification of either a topA activator or repressor was of interest. We found that SCO4804 acts as a topA transcriptional activator, since its elimination decreased topA promoter activity and protein level, while induction of SCO4804 resulted in higher activity of the topA promoter. Notably, our previous studies showed that elevated topA transcript level does not correspond with elevated TopA protein level, as well as or with significant changes in DNA supercoiling levels (Szafran et al., 2016). However, the fact that the topA transcript level increased and subsequently diminished shortly after SC04804 induction suggests that other mechanisms of maintaining TopA protein level are also activated. We previously suggested that the topA transcript and TopA protein levels are controlled by multiple regulatory strategies that act concertedly to preserve constant supercoiling level in Streptomyces (Szafran et al., 2016; Szafran et al., 2020). Additionally, we observed that SCO4804 induction influences not only TopA but also gyrase gene expression, indicating that the newly identified protein may be a component of the chromosome supercoiling maintenance system. The fact that transcription of sco4804 is activated in response to increased negative supercoiling corroborates its potential function as the regulator of topoisomerase activity.

\section{Conclusions}

To summarize, our screening approach is optimized for Streptomyces and allows the identification of both positive and negative regulators that control the expression of genes of interest by either direct or indirect mechanisms. As proven by our concept, the protein SCO4804 was found to be a component of a complex regulatory network involved in S. coelicolor chromosome supercoiling maintenance. Since the production of secondary metabolites is regulated by chromosomal topology, understanding complex transcriptional regulation in Streptomyces is crucial for the industrial application of these bacteria.

\section{Methods}

\section{Bacterial strains, plasmids, and growth conditions}

Basic DNA manipulation procedures were performed according to standard protocols (Sambrook and Russell, 2001). Unless otherwise stated, all enzymes and isolation kits were obtained from Thermo Fisher Scientific (Waltham, MA) and NEB (Ipswitch, MA). Bacterial media and antibiotics were purchased from 
Difco Laboratories (Detroit, MI) and Carl Roth (Karlsruhe, Germany), respectively. The S. coelicolor growth conditions and antibiotic concentrations, as well as the conjugation procedure, followed the general protocols described by Kieser et al, 2000. For induction, thiostrepton at concentrations of $0.5-10 \mu \mathrm{g} / \mathrm{ml}$ was added. Growth curves of the $S$. coelicolor strains were determined using the Bioscreen $\mathrm{C}$ device (Oy Growth Curves Ab Ltd., Helsinki, Finland). Cultures were grown in triplicate in 79 medium (Prauser and Falta, 1968) (300 $\mu \mathrm{l} /$ well), inoculated with $0.01 \mathrm{U} / \mathrm{ml}$ spores $(1 \mathrm{U}$ is defined as the volume of spore stock solution diluted up to $1 \mathrm{ml}$ with $\mathrm{OD}_{600 \mathrm{~nm}}=1$ ). The $S$. coelicolor and $E$. coli strains used in this study are shown in Table 1. The plasmids used in this study are shown in Table S1 (Supplementary materials).

\section{Table 1: Strains used in this study.}




\begin{tabular}{|c|c|c|}
\hline Name & Genotype & $\begin{array}{l}\text { Source or } \\
\text { reference }\end{array}$ \\
\hline \multicolumn{3}{|l|}{ S. coelicolor } \\
\hline M145 (WT) & SCP1- SCP2- & $\begin{array}{l}\text { Bentley et } \\
\text { al., } 2002\end{array}$ \\
\hline PS04 (TopA $\downarrow)$ & M145 $\Delta$ topA::scar attB ФC31::plJ6902topA & $\begin{array}{l}\text { Szafran et } \\
\text { al., } 2013\end{array}$ \\
\hline MG03 (WT-lux) & M145 attBФВТ1::pFLUXHptopA & $\begin{array}{l}\text { Szafran et } \\
\text { al., } 2016\end{array}$ \\
\hline $\begin{array}{l}\text { MG04 (TopA } \downarrow- \\
\text { lux) }\end{array}$ & $\begin{array}{l}\text { M145 } \triangle \text { topA::scar attBФC31::plJ6902topA } \\
\text { attBФВТ1::pFLUXHptopA }\end{array}$ & $\begin{array}{l}\text { Szafran et } \\
\text { al., } 2016\end{array}$ \\
\hline MG02 & M145 attВФВТ1::pFLUXH_permE & $\begin{array}{l}\text { Szafran et } \\
\text { al., } 2016\end{array}$ \\
\hline MG01 & M145 attBФВТ1::pFLUXH & $\begin{array}{l}\text { Szafran et } \\
\text { al., } 2016\end{array}$ \\
\hline lux-tn66 & MG01 tn5::sco4804 & This study \\
\hline lux-tn66RP & lux-tn66 pWHM3Spec & This study \\
\hline MS10 & M145 pWHM3Hyg & $\begin{array}{l}\text { Szafran et } \\
\text { al., } 2016\end{array}$ \\
\hline MS11 & $\begin{array}{l}\text { M145 } \triangle \text { topA::scar attBФC31::plJ6902topA } \\
\text { pWHM3Hyg }\end{array}$ & $\begin{array}{l}\text { Szafran et } \\
\text { al., } 2013\end{array}$ \\
\hline MG66 & MG01 attBФC31::plJ6902_sco4804 & This study \\
\hline MG66_RP & MG66 pWHM3Hyg & This study \\
\hline M145_plJ6902 & M145 attBФC31::plJ6902 & This study \\
\hline \multicolumn{3}{|l|}{ E. coli } \\
\hline $\mathrm{DH} 5 \mathrm{a}$ & 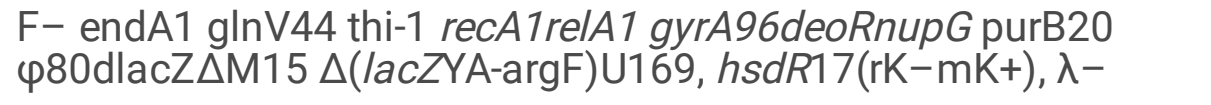 & Lab stock \\
\hline $\begin{array}{l}\text { ET12567 } \\
\text { pUZ8002 }\end{array}$ & dam-13::Tn 9dcm cat tet $h s d$ zjj-201::Tn 10 tra neo RP4 & $\begin{array}{l}\text { Kleser et al., } \\
2000\end{array}$ \\
\hline BW25113/plJ790 & $\begin{array}{l}\text { K12 derivative; } \triangle a r a B A D \triangle r h a B A D \lambda \text {-Red (gam bet exo) cat araC } \\
\text { rep101(Ts) }\end{array}$ & $\begin{array}{l}\text { Gust et al., } \\
2001\end{array}$ \\
\hline $\begin{array}{l}\text { BL21 (DE3) } \\
\text { groEL-groES } \\
\text { strain }\end{array}$ & 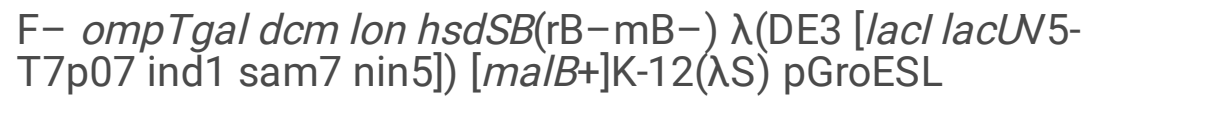 & $\begin{array}{l}\text { (Goloubinoff } \\
\text { et al., 1989) }\end{array}$ \\
\hline
\end{tabular}


To perform random transposon mutagenesis in S. coelicolor MG03, we used the pHL734 vector. Mutagenesis was performed according to a procedure described earlier (Xu et al., 2017). Briefly, E. coli ET12567 pUZ8002 harbouring the pHL734 plasmid was grown to $\mathrm{OD}_{600 \mathrm{~nm}}=0.5$ and conjugated with $5 \mathrm{U}$ of S. coelicolor MG03 (WT-lux) spores. The conjugated cell mixture was diluted $\left(10^{-4}-10^{-6}\right)$ and plated on MS agar supplemented with $10 \mathrm{mM} \mathrm{MgCl}_{2}$ and $60 \mathrm{mM} \mathrm{CaCl}_{2}$ to obtain single colonies. After 17 hours of growth at $30^{\circ} \mathrm{C}$, the plates were overlaid with $20 \mu \mathrm{l}$ per plate of each antibiotic below: nalidixic acid (25 $\mathrm{mg} / \mathrm{ml})$, apramycin $(50 \mathrm{mg} / \mathrm{ml})$ and hygromycin B $(50 \mathrm{mg} / \mathrm{ml})$. The obtained colonies were tested for luminescence intensity (see below), re-streaked on fresh MS agar plates supplemented with apramycin and hygromycin and used to establish liquid cultures. The positions of mini-Tn5 insertions in the $S$. coelicolor MG03 chromosome were identified using the rescue plasmid method. First, chromosomal DNA was isolated from a 24-hour culture in 79 medium of $S$. coelicolor transposon strains. Subsequently, $2 \mu \mathrm{g}$ of chromosomal DNA was digested with the Apal restriction enzyme (at $37^{\circ} \mathrm{C}$ overnight, $50 \mu \mathrm{l}$ total reaction volume), and then DNA was purified using a CleanUp kit (A\&A Biotechnology, Gdynia, Poland) and eluted with $15 \mu \mathrm{l}$ of ultrapure water. Then, $100-200 \mathrm{ng}$ of the Apal-digested DNA was re-ligated (at $4^{\circ} \mathrm{C}$ overnight, $20 \mu \mathrm{l}$ total volume of the reaction) using $1 \mu \mathrm{l}$ of T4 DNA ligase (NEB) to allow formation of a mini-E. coli replicative plasmid. Electrocompetent $E$. coli DH5a cells were transformed with the ligation products (using half of the reaction volume) and selected on apramycin LB agar plates. Plasmid DNA was isolated from single E. coli colonies using a Plasmid Screening Kit (Syngen Biotech, Wrocław, Poland) according to the manufacturer's instructions. The isolated plasmids were digested with the Apal restriction enzyme and analysed using gel electrophoresis, and plasmids exhibiting different digestion patterns were picked for subsequent DNA sequencing. Sequencing (Sigma-Aldrich, Saint Louis, MO) using UpS oligonucleotides identified the sites of mini-Tn5 insertion.

\section{Strain construction}

For inducible overexpression of the sc04804 gene, the pIJ6902_sc04804 plasmid was constructed. A DNA fragment encompassing the sco4804 gene with flanking EcoRI and Ndel restriction sites was synthesized and cloned into the pUC57 mini plasmid, yielding pUCmini_4804 (GenScript Biotech Corporation, New Jersey, US). The plJ6902_sc04804 plasmid was obtained by restriction cloning of the sco4804 insert into the plJ6902 plasmid using Ndel and EcoRI sites. The construct was then conjugated from E. coli ET12567 pUZ8002 into S. coelicolor MG03 (WT-lux strain), apramycin-resistant exconjugants were selected, and the plasmid presence in the obtained strain MG66 was confirmed by PCR using M13pUCr and sco4804_rv oligonucleotides.

To analyse DNA supercoiling in the $S$. coelicolortransposon mutant lux-tn66 strain, we modified the pWHM3Hyg reporter plasmid (Szafran et al., 2013) by substituting the hygromycin resistance cassette with the spectinomycin resistance gene using the Redirect system (Gust et al., 2004), oligonucleotides spect_fwd_2 and spect_rv and plasmid pIJ778 as a template, yielding pWHM3Spec. Next, we introduced the pWHM3Spec plasmid into the lux-tn66 transposon mutant strain via conjugation with E. coli ET12567 pUZ8002 (Kieser et al., 2000). The MG66_RP strain, which was also used for analysis of DNA 
supercoiling, was obtained by conjugation of the plJ6902_sc04804 plasmid into the MS10 strain (WT harbouring the pWHM3Hyg reporter plasmid).

As a control for the growth analysis of the MG66 strain induced with thiostrepton, we also constructed the M145_plJ6902 strain, in which the empty plasmid plJ6902 was introduced via conjugation into the M145 S. coelicolorstrain.

\section{Reporter gene activity assays}

To measure luciferase activity in liquid culture, strains containing the luxCDAEB operon (under the control of the topA promoter or under the control of the erm promoter) in the pFLUXH ФBT1 integrating vector were grown in liquid 79 medium for 24 hours at $30^{\circ} \mathrm{C}$ (in three biological replicates for each strain). Subsequently, the mycelium was collected by centrifugation, wet weight was determined, and mycelium was resuspended in $300 \mu \mathrm{l}$ of 79 medium. Measurement of the luciferase activity was performed in triplicate directly from the mycelium suspension for each biological sample in a $100 \mu$ l volume in 96-well microplates (Perkin Elmer, Waltham, MA) using the Infinite PRO Multimode Plate Reader (Tecan, Männedorf, Switzerland). The luminescence intensity was normalized against wet weight (units/100 mg of mycelium). Luminescence visualization on solid medium was performed on MS agar plates after 48 hours of growth at $30^{\circ} \mathrm{C}$, and luminescence detection was performed using a ChemiDocXRS+ device (BioRad, Hercules, CA).

\section{RNA isolation and RT-qPCR}

For gene expression analysis, RNA was isolated from S. coelicolor cultures grown for 18 hours (unless otherwise stated) in liquid 79 medium. Before harvesting, a 1/10 culture volume of 95\% EtOH saturated with phenol was added at a $5 \%$ final concentration to stabilize cellular RNA (Romero et al, 2014), and then mycelium was harvested by centrifugation and frozen in liquid nitrogen. Next, total RNA was isolated using Tri-Reagent (Sigma-Aldrich) according to the manufacturer's protocol. The RNA solution was transferred to a Total RNA Mini column (A\&A Biotechnology) and processed according to the manufacturer's instructions. The RNA samples were digested with Turbo DNase I (Invitrogen, Carlsbad, $\mathrm{CA})$ to remove traces of chromosomal DNA and then purified and concentrated using Clean-Up RNA Concentration (A\&A Biotechnology). Five hundred micrograms of RNA was used for CDNA synthesis with the Maxima First Strand cDNA Synthesis Kit (Thermo Fisher Scientific). cDNA samples were diluted 5 times and used as templates for quantitative PCR (qPCR, each reaction performed in triplicate) using PowerUp SYBR Green Master Mix (Thermo Fisher Scientific). The level of the topA transcript was quantified using $h r d B$ as a reference gene ( $\triangle \triangle C T$ method) (StepOnePlus Real-Time PCR system; Applied Biosystems, Foster City, CA). Isolated RNA was tested for DNA contamination by qPCR with oligonucleotides complementary to the $S$. coelicolorhrdB gene. The difference $>5 \mathrm{Ct}$ after $30 \mathrm{PCR}$ cycles between the RNA sample and the corresponding CDNA sample as a template showed that the RNA samples were DNA-free.

\section{DNA supercoiling assay}


Global DNA supercoiling in S. coelicolor strains was quantified using the pWHM3Hyg reporter plasmid (Szafran et al., 2013) or its modified version, pWHM3Spec (Table S1). The plasmids were isolated using alkaline lysis and column purification based on a modified version of the manufacturer's (Plasmid Screening Kit, Syngen) procedure. After 48 hours of growth in liquid 79 medium supplemented with hygromycin or spectinomycin, S. coelicolor mycelium was collected by centrifugation, resuspended in PZ buffer containing $25 \mathrm{mg} / \mathrm{ml}$ lysozyme and incubated at $30^{\circ} \mathrm{C}$ for $5 \mathrm{~min}$. The subsequent steps followed the manufacturer's protocol. The isolated reporter plasmids were resolved in $0.8 \%$ agarose in Tris-acetateEDTA (TAE) buffer (40 mM Tris, $20 \mathrm{mM}$ acetic acid, and $1 \mathrm{mM}$ EDTA, pH 8.3) in the presence of $4.6 \mu \mathrm{M}$ chloroquine at a voltage of $20 \mathrm{~V}$. To visualize topoisomers, the gel was stained with ethidium bromide for $30 \mathrm{~min}$ at room temperature. The experiment was repeated twice. The topoisomer distribution was analysed using ImageJ software.

\section{TopA level quantification using Western blotting}

For TopA level quantification, S. coelicolor $5 \mathrm{ml}$ liquid cultures in 79 medium were cultivated for 24 hours. Next, the cell pellet was collected by centrifugation, resuspended in phosphate-buffered saline (PBS), sonicated and centrifuged. The cell lysates ( $5 \mu \mathrm{g}$ of total protein) were separated by $10 \%$ SDS-PAGE according to standard procedures (Laemmli, 1970). After electrophoresis, the resolved proteins were stained overnight with PageBlue Protein Staining Solution (Thermo Fisher Scientific) or transferred to a nitrocellulose membrane and blocked with $2 \%$ milk in TBST $(20 \mathrm{mM}$ Tris, $150 \mathrm{mM} \mathrm{NaCl}, 0.1 \%$ Tween 20 , $\mathrm{pH}$ 7.4-7.6). The blots were subsequently incubated with rabbit polyclonal TopA antiserum (1:10,000 in TBST; 1-hour incubation; Szafran et al., 2013) and visualized using alkaline phosphatase-conjugated goat anti-rabbit antibodies (1:5000) (Sigma-Aldrich). The band intensities were analysed using ImageJ software, comparing the TopA band intensity of particular mutants to the wild-type reference.

\section{Structure prediction and homologue analysis}

SC04804 protein structure prediction was performed using the Robetta Web Server and "TrRefineRosetta" modelling method (Raman et al., 2009; Song, et al., 2013), as well as using PredictProtein (Yachdav et al., 2014). Homologue searching was performed using HOGENOM (Penel et al., 2009).

\section{Abbreviations}

WT- wild type; RNAP- RNA polymerase, TF- transcription factor; TAE- Tris-acetate-EDTA buffer; TBE-Trisborate-EDTA buffer, MS- mannitol soya flour agar; PBS- phosphate-buffered saline; TBST- Tris-buffered saline with $0.1 \%$ Tween 20 detergent.

\section{Declarations}

\section{Ethics approval and consent to participate}

Not applicable. 


\section{Consent for publication}

Not applicable.

\section{Availability of data and materials}

The datasets used and analysed during the current study are available from the corresponding author on reasonable request.

\section{Competing interest}

The authors declare that they have no competing interests.

\section{Funding}

This study was supported by the National Science Centre, Poland: PRELUDIUM grant 2016/23/N/NZ2/01169 to MGJ.

\section{Authors' contributions}

MGJ performed all experiments described in this paper and was a major contributor in writing the manuscript. MS contributed to the conception of the work, data interpretation and revision of the manuscript; DJ made substantial contributions to interpretation of data and writing the manuscript.

\section{Acknowledgements}

Not applicable.

\section{References}

Ahmed, W., Menon, S., D. N. B. Karthik, P. V., Nagaraja, V. Autoregulation of Topoisomerase I Expression by Supercoiling Sensitive Transcription. Nucleic Acids Res2016, 44 (4), 1541-1552.

Baptist, G., Pinel, C., Ranquet, C., Izard, J., Ropers, D., de Jong, H., Geiselmann, J. A Genome-Wide Screen for Identifying All Regulators of a Target Gene. Nucleic Acids Res2013, 41 (17), e164.

Bentley S. D., Chater K. F., Hopwood D. A. Complete genome sequence of the model actinomycete Streptomyces coelicolor A3(2) | Nature 2002, 417,141-147.

Bilyk, B., Weber, S., Myronovskyi, M., Bilyk, O., Petzke, L., Luzhetskyy, A. In Vivo Random Mutagenesis of Streptomycetes Using Mariner-Based Transposon Himar1. App/ Microbiol Biotechno/2013, 97 (1), 351359.

Bouvet, P. Determination of Nucleic Acid Recognition Sequences by SELEX. Methods Mol Bio/2001, 148, 603-610. 
Browning, D. F., Busby, S. J. W. Local and Global Regulation of Transcription Initiation in Bacteria. Nat Rev Microbio/2016, 14 (10), 638-650.

Burda, W. N., Miller, H. K., Krute, C. N., Leighton, S. L., Carroll, R. K., Shaw, L. N. Investigating the Genetic Regulation of the ECF Sigma Factor $\Sigma$ S in Staphylococcus Aureus. BMC Microbio/2014, 14, 280.

Bush, M. J., Chandra, G., Al-Bassam, M. M., Findlay, K. C., Buttner, M. J. BldC Delays Entry into Development To Produce a Sustained Period of Vegetative Growth in Streptomyces Venezuelae. mBio2019, 10 (1).

Champoux, J. J. DNA Topoisomerases: Structure, Function, and Mechanism. Annu. Rev. Biochem.2001, $70(1), 369-413$.

Chater, K. F. Streptomyces Inside-out: A New Perspective on the Bacteria That Provide Us with Antibiotics. Philos Trans R Soc Lond B Biol Sci2006, 361 (1469), 761-768.

Chater, K. F. Recent Advances in Understanding Streptomyces. F1000Res2016, 5, 2795.

Chen, L., Wang, Y., Guo, H., Xu, M., Deng, Z., Tao, M. High-Throughput Screening for Streptomyces Antibiotic Biosynthesis Activators. App/ Environ Microbio/2012, 78 (12), 4526-4528.

Craney, A., Hohenauer, T., Xu, Y., Navani, N. K., Li, Y., Nodwell, J. A Synthetic LuxCDABE Gene Cluster Optimized for Expression in High-GC Bacteria. Nucleic Acids Res2007, 35 (6), e46.

den Hengst, C. D., Tran, N. T., Bibb, M. J., Chandra, G., Leskiw, B. K., Buttner, M. J. Genes Essential for Morphological Development and Antibiotic Production in Streptomyces Coelicolor Are Targets of BldD during Vegetative Growth. Mol Microbio/2010, 78 (2), 361-379.

Diggle, S. P., Winzer, K., Lazdunski, A., Williams, P., Cámara, M. Advancing the Quorum in Pseudomonas Aeruginosa: MvaT and the Regulation of N-Acylhomoserine Lactone Production and Virulence Gene Expression. J Bacterio/2002, 184 (10), 2576-2586.

Donczew, M., Mackiewicz, P., Wróbel, A., Flärdh, K., Zakrzewska-Czerwińska, J., Jakimowicz, D. ParA and ParB Coordinate Chromosome Segregation with Cell Elongation and Division during Streptomyces Sporulation. Open Bio/2016, 6 (4).

Dorman, C. J., Corcoran, C. P. Bacterial DNA Topology and Infectious Disease. Nucleic Acids Res2009, 37 (3), 672-678.

Ferrándiz, M.-J., Arnanz, C., Martín-Galiano, A. J., Rodríguez-Martín, C., de la Campa, A. G. Role of Global and Local Topology in the Regulation of Gene Expression in Streptococcus Pneumoniae. PLoS One2014, 9 (7), e101574. 
Flärdh, K., Buttner, M. J. Streptomyces Morphogenetics: Dissecting Differentiation in a Filamentous Bacterium. Nat Rev Microbio/2009, 7(1), 36-49.

Floriano, B., Bibb, M. AfsR Is a Pleiotropic but Conditionally Required Regulatory Gene for Antibiotic Production in Streptomyces Coelicolor A3(2). Mol Microbio/1996, 21 (2), 385-396.

Gehrke, E. J., Zhang, X., Pimentel-Elardo, S. M., Johnson, A. R., Rees, C. A., Jones, S. E., Hindra, Gehrke, S. S., Turvey, S., Boursalie, S., Hill, J. E., Carlson, E. E., Nodwell, J. R., Elliot, M. A. Silencing Cryptic Specialized Metabolism in Streptomyces by the Nucleoid-Associated Protein Lsr2. eLife, 2019, 8:e47691.

Gmuender, H., Kuratli, K., Di Padova K., Gray, C. P., Keck, W., Evers, S. Gene Expression Changes Triggered by Exposure of Haemophilus Influenzae to Novobiocin or Ciprofloxacin: Combined Transcription and Translation Analysis. Genome Res2001, 11 (1), 28-42.

Goloubinoff, P., Gatenby, A. A., Lorimer, G. H. GroE Heat-Shock Proteins Promote Assembly of Foreign Prokaryotic Ribulose Bisphosphate Carboxylase Oligomers in Escherichia Coli. Nature1989, 337(6202), 44-47.

Guo, M., Feng, H., Zhang, J., Wang, W., Wang, Y., Li, Y., Gao, C., Chen, H., Feng, Y., He, Z.-G. Dissecting Transcription Regulatory Pathways through a New Bacterial One-Hybrid Reporter System. Genome Res2009, 19 (7), 1301-1308.

Gust, B., Challis, G. L., Fowler, K., Kieser, T., Chater, K. F. PCR-Targeted Streptomyces Gene Replacement Identifies a Protein Domain Needed for Biosynthesis of the Sesquiterpene Soil Odor Geosmin. Proc Natl Acad Sci U S A2003, 100 (4), 1541-1546.

Hillerich, B., Westpheling, J. A New GntR Family Transcriptional Regulator in Streptomyces Coelicolor Is Required for Morphogenesis and Antibiotic Production and Controls Transcription of an ABC Transporter in Response to Carbon Source. J Bacterio/2006, 188 (21), 7477-7487.

Hong, S. K., Kito, M., Beppu, T., Horinouchi, S. Phosphorylation of the AfsR Product, a Global Regulatory Protein for Secondary-Metabolite Formation in Streptomyces Coelicolor A3(2). J Bacterio/1991, 173 (7), 2311-2318.

Horbal, L., Fedorenko, V., Bechthold, A., Luzhetskyy, A. A Transposon-Based Strategy to Identify the Regulatory Gene Network Responsible for Landomycin E Biosynthesis. FEMS Microbiology Letters2013, $342(2), 138-146$.

Hrdlickova, R., Toloue, M., Tian, B. RNA-Seq Methods for Transcriptome Analysis. Wiley Interdiscip Rev RNA2017, 8(1).

Huang, H., Shao, X., Xie, Y., Wang, T., Zhang, Y., Wang, X., Deng, X. An Integrated Genomic Regulatory Network of Virulence-Related Transcriptional Factors in Pseudomonas Aeruginosa. Nat Commun2019, 10. 
Huang, J., Shi, J., Molle, V., Sohlberg, B., Weaver, D., Bibb, M. J., Karoonuthaisiri, N., Lih, C.-J., Kao, C. M., Buttner, M. J., Cohen, S. N. Cross-Regulation among Disparate Antibiotic Biosynthetic Pathways of Streptomyces Coelicolor. Molecular Microbiology2005, 58 (5), 1276-1287.

Johannes, F., Wardenaar, R., Colomé-Tatché, M., Mousson, F., de Graaf, P., Mokry, M., Guryev, V., Timmers, H. T. M., Cuppen, E., Jansen, R. C. Comparing Genome-Wide Chromatin Profiles Using ChIP-Chip or ChIPSeq. Bioinformatics2010, $26(8), 1000-1006$.

Kieser, T., Bibb, M. J., Buttner, M. J., Chater, K. F., Hopwood, D. A. Practical Streptomyces Genetics, The John Innes Foundation: Norwich, 2000.

Kuscer, E., Coates, N., Challis, I., Gregory, M., Wilkinson, B., Sheridan, R., Petković, H. Roles of RapH and RapG in Positive Regulation of Rapamycin Biosynthesis in Streptomyces Hygroscopicus. J Bacterio/2007, 189 (13), 4756-4763.

Laemmli, U. K. Cleavage of Structural Proteins during the Assembly of the Head of Bacteriophage T4. Nature1970, 227 (5259), 680-685.

Lloyd, G., Landini, P., Busby, S. Activation and Repression of Transcription Initiation in Bacteria. Essays Biochem2001, 37, 17-31.

Luo, W., Miao, J., Feng, Z., Lu, R., Sun, X., Zhang, B., Ding, W., Lu, Y., Wang, Y., Chi, X., Ge, Y. Construction of a $\beta$-Galactosidase-Gene-Based Fusion Is Convenient for Screening Candidate Genes Involved in Regulation of Pyrrolnitrin Biosynthesis in Pseudomonas Chlororaphis G05. J Gen Appl Microbio/2018, 64 (6), 259-268.

Luo, S., Chen, X.-A., Mao, X.-M., Li, Y.-Q. Transposon-Based Identification of a Negative Regulator for the Antibiotic Hyper-Production in Streptomyces. App/ Microbiol Biotechno/2018a, 102 (15), 6581-6592.

McDonough, E., Lazinski, D. W., Camilli, A. Identification of in Vivo Regulators of the Vibrio Cholerae Xds Gene Using a High-Throughput Genetic Selection. Mol Microbio/2014, 92 (2), 302-315.

McHenney, M. A., Baltz, R. H. Gene Transfer and Transposition Mutagenesis in Streptomyces Roseosporus: Mapping of Insertions That Influence Daptomycin or Pigment Production. Microbiology (Reading)1996, 142 ( Pt 9), 2363-2373.

McLean, T. C., Wilkinson, B., Hutchings, M. I., Devine, R. Dissolution of the Disparate: Co-Ordinate Regulation in Antibiotic Biosynthesis. Antibiotics (Basel)2019, 8 (2).

Meng, X., Brodsky, M. H., Wolfe, S. A. A Bacterial One-Hybrid System for Determining the DNA-Binding Specificity of Transcription Factors. Nat Biotechno/2005, 23 (8), 988-994.

Menzel, R., Gellert, M. Regulation of the Genes for E. Coli DNA Gyrase: Homeostatic Control of DNA Supercoiling. Cel/1983, 34 (1), 105-113. 
Nett, M., Ikeda, H., Moore, B. S. Genomic Basis for Natural Product Biosynthetic Diversity in the Actinomycetes. Nat Prod Rep2009, 26 (11), 1362-1384.

Park, S.-S., Ko, B. J., Kim, B.-G. Mass Spectrometric Screening of Transcriptional Regulators Using DNA Affinity Capture Assay. Anal Biochem2005, 344 (1), 152-154.

Park, S.-S., Yang, Y.-H., Song, E., Kim, E.-J., Kim, W. S., Sohng, J. K., Lee, H. C., Liou, K. K., Kim, B.-G. Mass Spectrometric Screening of Transcriptional Regulators Involved in Antibiotic Biosynthesis in Streptomyces Coelicolor A3(2). J Ind Microbiol Biotechno/2009, 36 (8), 1073-1083.

Park, D.-W., Kim, S.-S., Nam, M.-K., Kim, G.-Y., Kim, J., Rhim, H. Improved Recovery of Active GST-Fusion Proteins from Insoluble Aggregates: Solubilization and Purification Conditions Using PKM2 and HtrA2 as Model Proteins. BMB Rep2011, 44 (4), 279-284.

Penel, S., Arigon, A.-M., Dufayard, J.-F., Sertier, A.-S., Daubin, V., Duret, L., Gouy, M., Perrière, G. Databases of Homologous Gene Families for Comparative Genomics. BMC Bioinformatics2009, 10 (Suppl 6), S3.

Peter, B. J., Arsuaga, J., Breier, A. M., Khodursky, A. B., Brown, P. O., Cozzarelli, N. R. Genomic Transcriptional Response to Loss of Chromosomal Supercoiling in Escherichia Coli. Genome Bio/2004, 5 (11), R87.

Prauser, H., Falta, G. Phage sensitivity, cell wall composition and taxonomy of actinomycetes. $Z$ Allg Mikrobiol. 1968, 8(1), 39-46.

Raman, S., Vernon, R., Thompson, J., Tyka, M., Sadreyev, R., Pei, J., Kim, D., Kellogg, E., DiMaio, F., Lange, O., Kinch, L., Sheffler, W., Kim, B.-H., Das, R., Grishin, N. V., Baker, D. Structure Prediction for CASP8 with AllAtom Refinement Using Rosetta. Proteins2009, 77 (0 9), 89-99.

Romero, D. A., Hasan, A. H., Lin, Y.-F., Kime, L., Ruiz-Larrabeiti, O., Urem, M., Bucca, G., Mamanova, L., Laing, E. E., van Wezel, G. P., Smith, C. P., Kaberdin, V. R., McDowall, K. J. A Comparison of Key Aspects of Gene Regulation in Streptomyces Coelicolor and Escherichia Coli Using Nucleotide-Resolution Transcription Maps Produced in Parallel by Global and Differential RNA Sequencing. Mol Microbio/2014, 94(5), 963-987.

Romero-Rodríguez, A., Robledo-Casados, I., Sánchez, S. An Overview on Transcriptional Regulators in Streptomyces. Biochim Biophys Acta2015, 1849 (8), 1017-1039.

Rui, S., Tse-Dinh, Y.-C. Topoisomerase Function during Bacterial Responses to Environmental Challenge. Front Biosci2003, 8, d256-263.

Sambrook, J., Russell, D. W. Molecular Cloning: A Laboratory Manual, CSHL Press, 2001.

Song, Y., DiMaio, F., Wang, R. Y.-R., Kim, D., Miles, C., Brunette, T., Thompson, J., Baker, D. High Resolution Comparative Modeling with RosettaCM. Structure2013, 21 (10). 
Szafran, M., Skut, P., Ditkowski, B., Ginda, K., Chandra, G., Zakrzewska-Czerwińska, J., Jakimowicz, D. Topoisomerase I (TopA) Is Recruited to ParB Complexes and Is Required for Proper Chromosome Organization during Streptomyces Coelicolor Sporulation. J Bacterio/2013, 195 (19), 4445-4455.

Szafran, M. J., Strick, T., Strzałka, A., Zakrzewska-Czerwińska, J., Jakimowicz, D. A Highly Processive Topoisomerase I: Studies at the Single-Molecule Level. Nucleic Acids Res2014, 42 (12), 7935-7946.

Szafran, M. J., Gongerowska, M., Gutkowski, P., Zakrzewska-Czerwińska, J., Jakimowicz, D. The Coordinated Positive Regulation of Topoisomerase Genes Maintains Topological Homeostasis in Streptomyces Coelicolor. J Bacterio/2016, 198 (21), 3016-3028.

Szafran, M. J., Gongerowska, M., Małecki, T., Elliot, M., Jakimowicz, D. Transcriptional Response of Streptomyces Coelicolor to Rapid Chromosome Relaxation or Long-Term Supercoiling Imbalance. Front Microbio/2019, 10, 1605.

Szafran, M. J., Jakimowicz, D., Elliot, M. A. Compaction and Control-the Role of Chromosome-Organizing Proteins in Streptomyces. FEMS Microbiol Rev2020, 44 (6), 725-739.

Szostek, B. A., Rather, P. N. Regulation of the Swarming Inhibitor DisA in Proteus Mirabilis. $J$ Bacterio/2013, 195 (14), 3237-3243.

Truong-Bolduc, Q. C., Hooper, D. C. Identification of a Staphylococcus Aureus Efflux Pump Regulator Using a DNA-Protein Affinity Technique. Methods Mol Bio/2018, 1700, 269-291.

Tse-Dinh, Y. C. Regulation of the Escherichia Coli DNA Topoisomerase I Gene by DNA Supercoiling. Nucleic Acids Res1985, 13 (13), 4751-4763.

Volff, J. N., Altenbuchner, J. High Frequency Transposition of the Tn5 Derivative Tn5493 in Streptomyces Lividans. Gene1997, 194 (1), 81-86.

Wang, W., Li, X., Li, Y., Li, S., Fan, K., Yang, K. A Genetic Biosensor for Identification of Transcriptional Repressors of Target Promoters. Sci Rep2015, 5, 15887.

Weaden, J., Dyson, P. Transposon Mutagenesis with IS6100 in the Avermectin-Producer Streptomyces Avermitilis. Microbiology1998, 144, 1963-1970.

Webber, M. A., Ricci, V., Whitehead, R., Patel, M., Fookes, M., Ivens, A., Piddock, L. J. V. Clinically Relevant Mutant DNA Gyrase Alters Supercoiling, Changes the Transcriptome, and Confers Multidrug Resistance. mBio2013, 4 (4).

Wei, J., He, L., Niu, G. Regulation of Antibiotic Biosynthesis in Actinomycetes: Perspectives and Challenges. Synth Syst Biotechno/2018, 3 (4), 229-235. 
Widenbrant, E. M., Kao, C. M. Introduction of the Foreign Transposon Tn4560 in Streptomyces Coelicolor Leads to Genetic Instability near the Native Insertion Sequence IS1649. J Bacterio/2007, 189 (24), 91089116.

Wilson, D. J., Xue, Y., Reynolds, K. A., Sherman, D. H. Characterization and Analysis of the PikD Regulatory Factor in the Pikromycin Biosynthetic Pathway of Streptomyces Venezuelae. J Bacterio/2001, 183 (11), 3468-3475.

Wolanski, M., Donczew, R., Kois-Ostrowska, A., Masiewicz, P., Jakimowicz, D., Zakrzewska-Czerwinska, J. The Level of AdpA Directly Affects Expression of Developmental Genes in Streptomyces Coelicolor. $J$ Bacterio/2011, 193 (22), 6358-6365.

Wu, J., Smith, L. T., Plass, C., Huang, T. H.-M. ChIP-Chip Comes of Age for Genome-Wide Functional Analysis. Cancer Res2006, 66 (14), 6899-6902.

Xia, H., Zhan, X., Mao, X.-M., Li, Y.-Q. The Regulatory Cascades of Antibiotic Production in Streptomyces. World J Microbiol Biotechno/2020, 36 (1), 13.

Xu, Z., Wang, Y., Chater, K. F., Ou, H.-Y., Xu, H. H., Deng, Z., Tao, M. Large-Scale Transposition Mutagenesis of Streptomyces Coelicolor Identifies Hundreds of Genes Influencing Antibiotic Biosynthesis. Appl Environ Microbio/2017, 83 (6).

Yachdav, G., Kloppmann, E., Kajan, L., Hecht, M., Goldberg, T., Hamp, T., Hönigschmid, P., Schafferhans, A., Roos, M., Bernhofer, M., Richter, L., Ashkenazy, H., Punta, M., Schlessinger, A., Bromberg, Y., Schneider, R., Vriend, G., Sander, C., Ben-Tal, N., Rost, B. PredictProtein-an Open Resource for Online Prediction of Protein Structural and Functional Features. Nucleic Acids Res2014, 42 (Web Server issue), W337-343.

Yamazaki, H., Tomono, A., Ohnishi, Y., Horinouchi, S. DNA-Binding Specificity of AdpA, a Transcriptional Activator in the A-Factor Regulatory Cascade in Streptomyces Griseus. Mol Microbio/2004, 53 (2), 555572.

\section{Figures}




\section{Fig. 1}

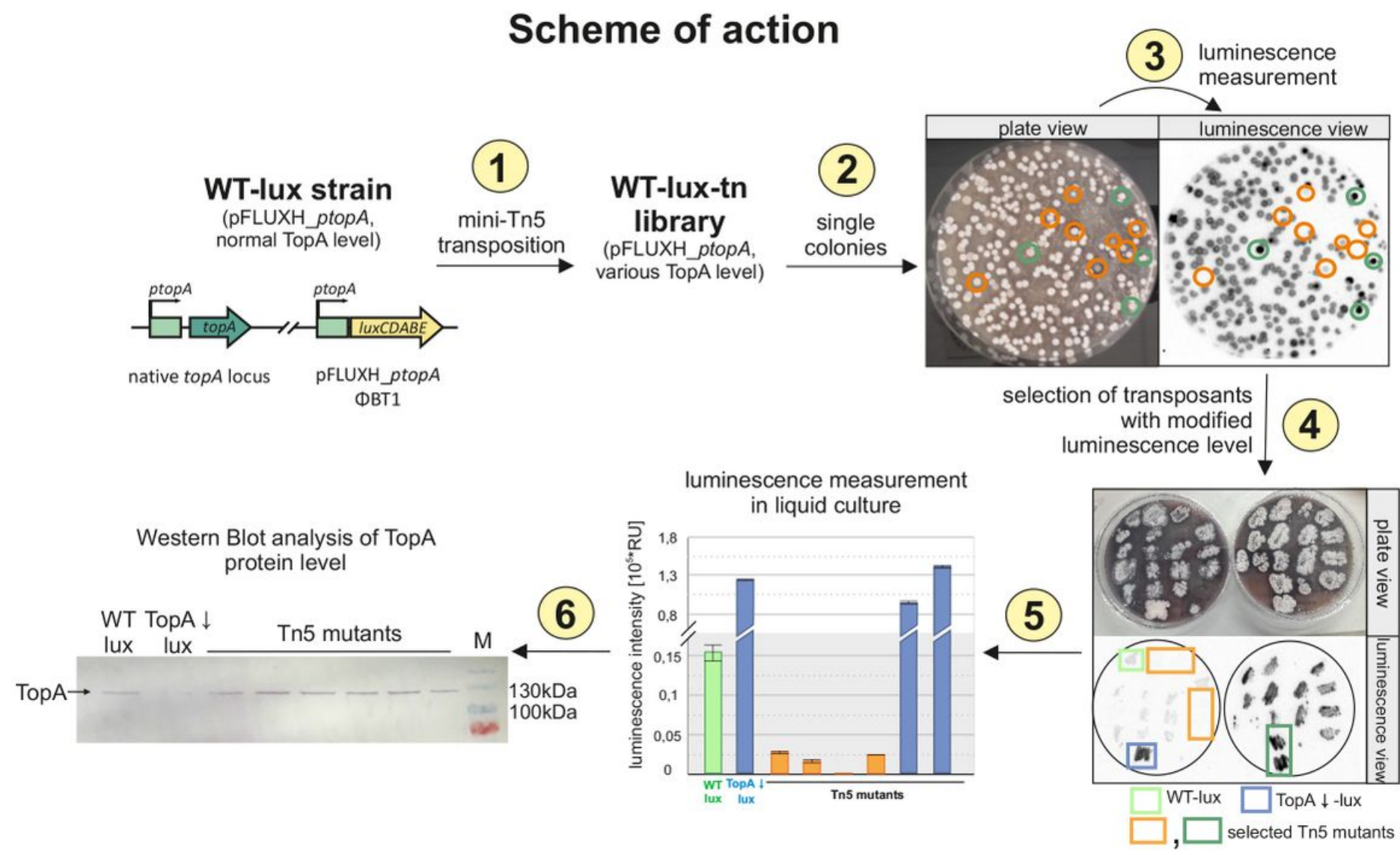

Figure 1

Scheme of random Tn5 transposon mutagenesis in the S. coelicolor WT-lux reporter strain. 1. Random transposon mutagenesis of the WT-lux strain (MG03) with a mini-Tn5 transposon. 2. The WT-lux-tn mutant library consisted of approximately 8300 single colonies obtained on MS agar plates. 3 . Measurement of the luminescence of WT-lux-tn library single colonies. 4. Selection of colonies with altered light emission compared to the WT-lux paternal strain and TopA-depleted lux strain (MG04, high activity of topA promoter). 5 . The luminescence of selected colonies from the WT-lux-tn library measured in liquid culture compared with the WT-lux strain and TopA-depleted lux strain (high activity of the topA promoter). RU - relative luminescence units. 6 . Western blot analysis of TopA protein level in cell lysates of selected colonies from the WT-lux-tn library with anti-TopA polyclonal antibodies. M - molecular mass marker. 
A

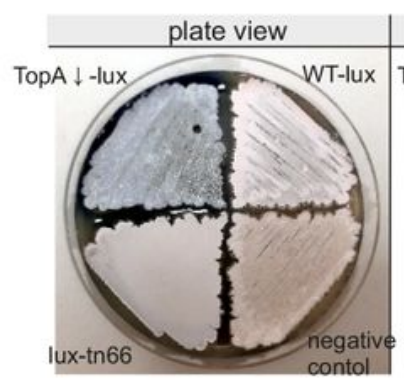

C

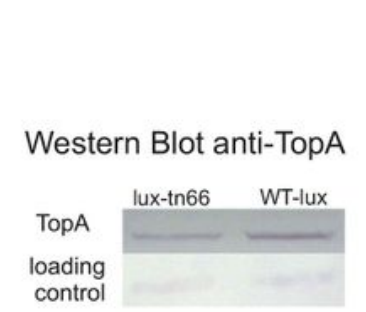

D

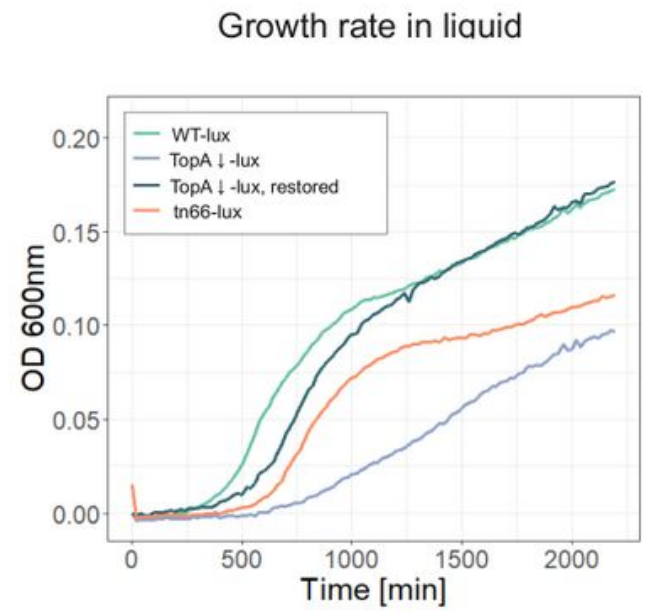

RT-PCR
B

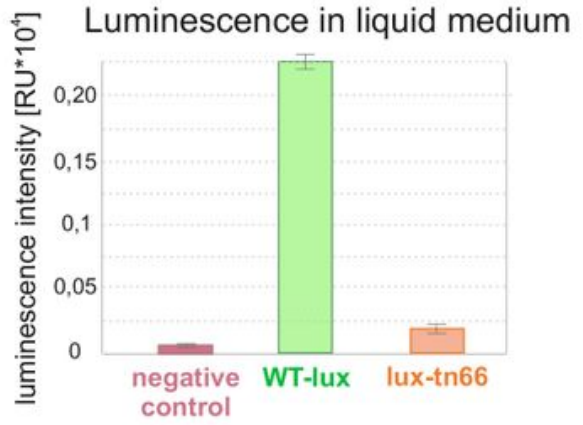

E $\begin{gathered}\text { Supercoiling } \\ \text { of the reporter plasmid }\end{gathered}$

topA transcript level
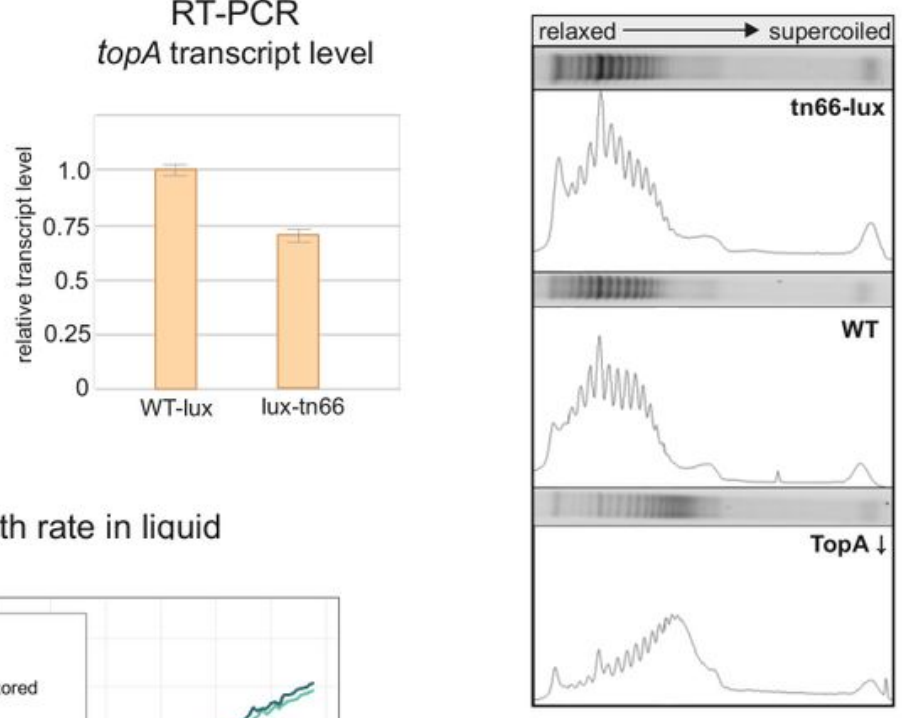

F

RT-PCR

gyrB transcript level

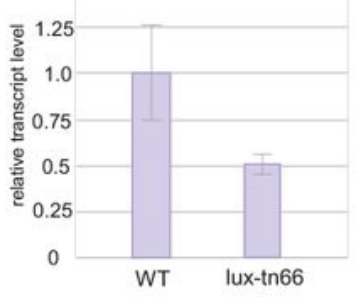

\section{Figure 2}

Phenotype of the lux-tn66 transposon strain. A. Growth and luminescence of the lux-tn66 transposon strain on solid MS medium in comparison to the WT-lux strain (MG03), TopA-depleted lux strain (MG04) and the negative control - wild type strain with empty pFLUXH vector (MG01). Left panel: plate view (after 5 days of growth), right panel: luminescence intensity (after 48 hours). B. Luminescence of mutant reporter strains after 24 hours of growth in liquid 79 medium compared to the WT-lux (MG03) and the 
negative control-wild-type strain with empty pFLUXH vector (MG01). C. Western blot analysis of TopA protein level (top panel) and the relative transcription of the native topA gene in the mutant lux-tn66 strain determined using RT-qPCR analysis performed on 24-hour 79 medium cultures, compared to the WT-lux strain. D. The growth curves of the lux-tn66 strain (79 medium, Bioscreen C, measurements every 20 minutes) compared to the WT-Iux (MG03) and TopA-depleted lux strain (MG04), as well as to MG04 with restored TopA protein level (after induction with $0.5 \mu \mathrm{g} / \mathrm{ml}$ thiostrepton). E. Supercoiling density of the reporter plasmids pWHM3Hyg or pWHM3Spec isolated from the transposon mutant lux-tn66 derivative (lux-tn66_RP) strain, the wild-type strain derivative (MS10) and the TopA-depleted (MS11) strain (representative image of two independent experiments). The figure shows topoisomers detected in agarose gel as well as band intensity measurements performed using ImageJ software. F. The level of gyrB transcript in lux-tn66 strain determined using RT-qPCR analysis performed on 24-hour 79 medium cultures, compared to the WT-lux strain (MG03). 


\section{Fig. 3}

A

Genomic localization of sco4804 gene and transposition site

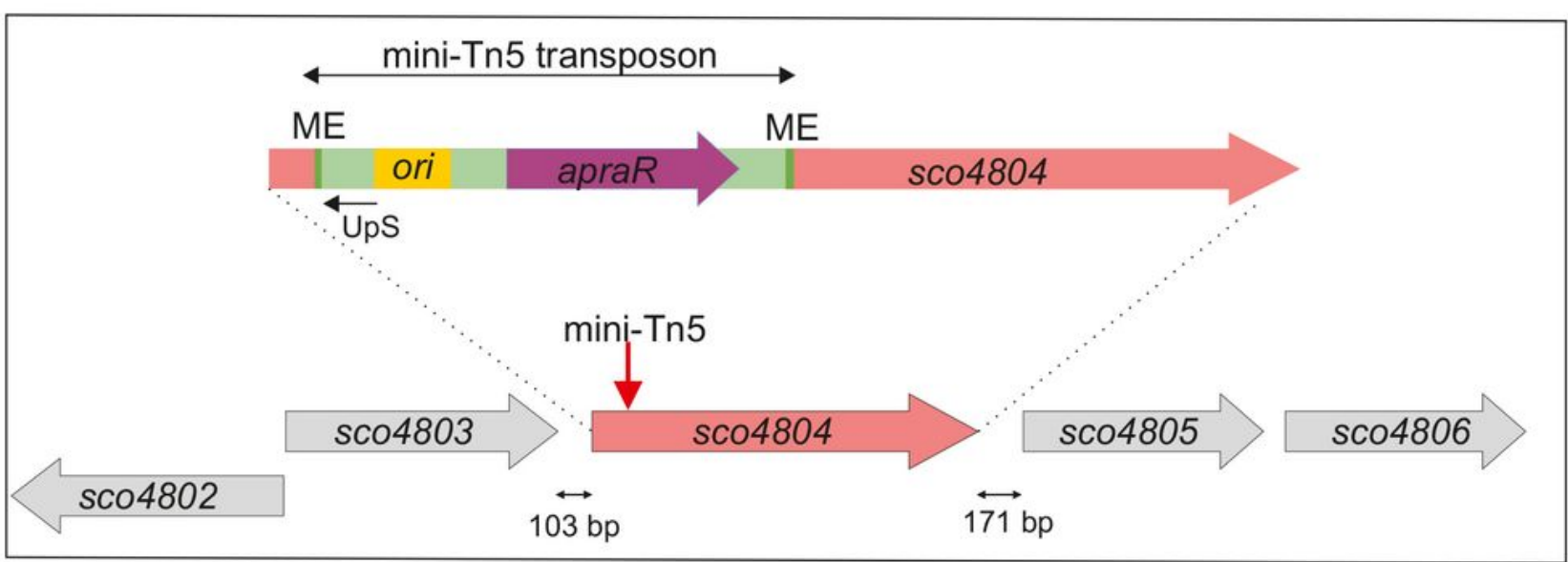

B

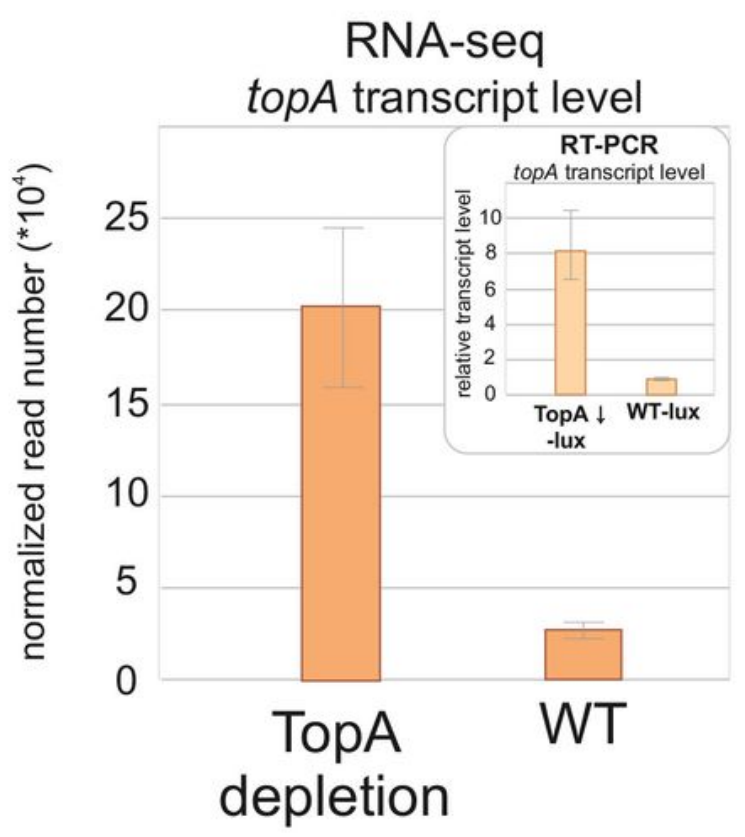

Figure 3

Genomic localization and supercoiling-dependent transcription of sco4804. A. Transposition site in luxtn66 strain. ME (dark green) - the mosaic end sequence; ori (yellow) - origin of replication from pUC vector for DNA replication in E. coli; apraR (dark violet) - apramycin resistance gene; UpS - primer used for recognition of mini-Tn5 insertion site. The red arrow shows the identified site of the mini-Tn5 insertion. The black arrows at the bottom of the scheme show the distance between neighbouring genes. B. RNA- 
Seq-based analysis of the expression level of sco4804 in the TopA-depleted (PS04) and control wild-type (M145) strains performed for 18-hour YEME/TSB cultures, normalized by the upper quartile (Szafran et al., 2019). The error bars correspond to standard deviations calculated for four independent biological replicates. Inset: the relative transcription of sco4804 in the TopA-depleted lux (MG04) and WT-lux reporter (MG03) strains calculated using RT-qPCR analysis performed for 24-hour cultures in 79 medium.

\section{Fig. 4}

A

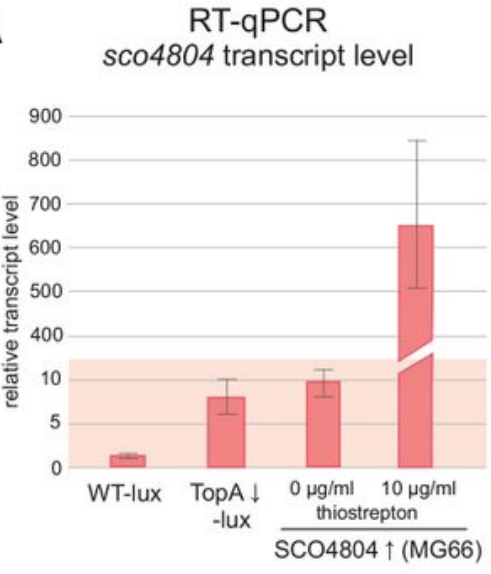

C

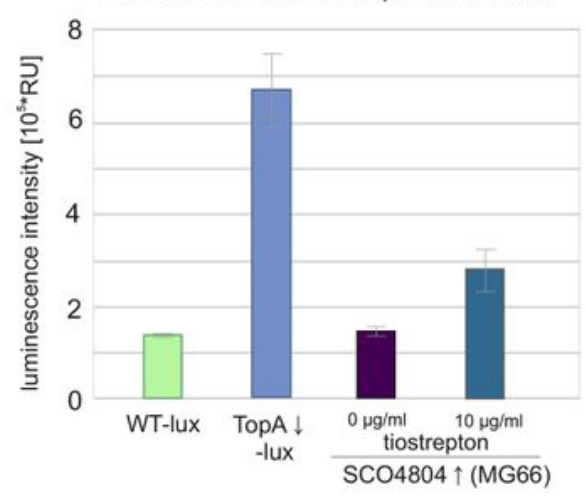

E

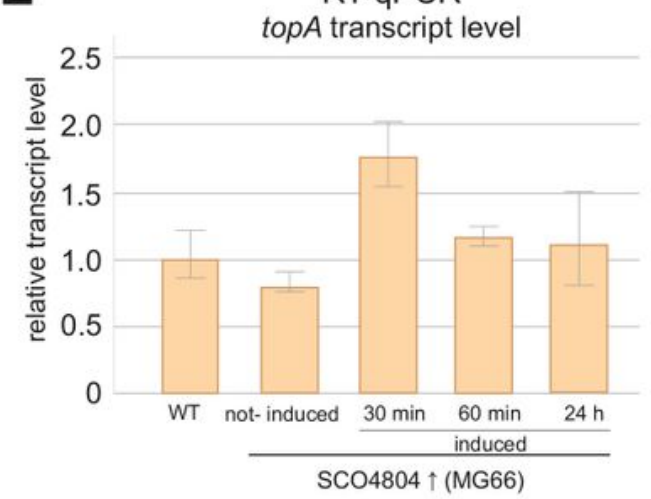

B Growth of SCO4804 $\uparrow$ (MG66) strain

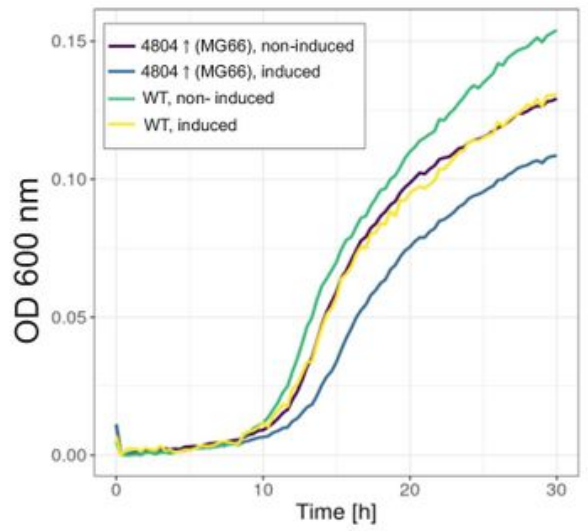

D Luminescence on solid medium

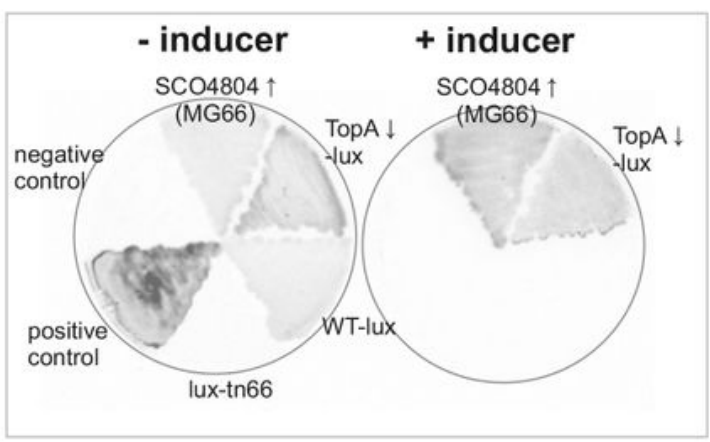

F

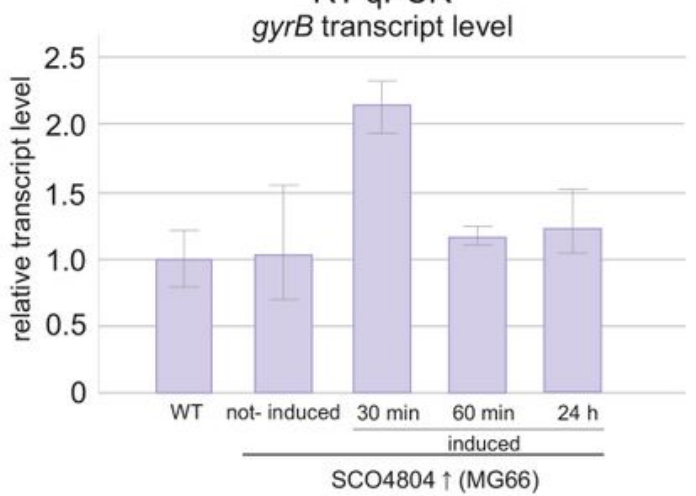

Figure 4 
Phenotype of the SCO4804 overproducing strain. A. RT-qPCR analysis of the sco4804 transcript level in the MG66 strain (non-induced and induced with $10 \mu \mathrm{g} / \mathrm{ml}$ thiostrepton) compared to the WT-lux (MG03) and TopA-depleted lux (MG04) strains performed for 24-hour cultures grown in 79 medium. B. The growth curves of the non-induced MG66 strain and MG66 induced with $10 \mu \mathrm{g} / \mathrm{ml}$ thiostrepton (79 medium, Bioscreen C, measurements every 20 minutes) compared to the WT-lux strain (MG03). C. Measurement of luminescence of the MG66 strain in the absence or in the presence of the sco4804 inducer ( 0 and 10 $\square \mathrm{g} / \mathrm{ml}$ of thiostrepton) indicating the changes of topA promoter activity, performed in liquid 79 medium after 24 hours of growth and compared to the WT-lux (MG03) and TopA-depleted lux (MGO4) strains. D. Luminescence of MG66 indicating the activity of the topA promoter controlling the lux reporter genes after 48 hours of growth on solid MS agar plates, without and with the inducer ( $10 \mu \mathrm{g} / \mathrm{ml}$ thiostrepton), as compared to the WT-lux (MG03) and TopA- depleted lux (MGO4) strain, negative control (the wild-type strain with empty pFLUXH vector (MG01)) and positive control (the wild type strain with pFLUXH_permE (MG02)). E. RT-qPCR analysis of the relative transcription of the topA gene in the SCO4804 overproducing strain (MG66) cultured in 79 medium for 24 hours and induced with $10 \mu \mathrm{g} / \mathrm{ml}$ thiostrepton for 30 minutes, 60 minutes or cultured for 24 hours in the presence of the inducer. The data were compared to the non-induced control and WT-lux strain (MG03) grown for 24 hours in 79 medium. F. RT-qPCR analysis of the relative transcription of the gyrB gene in the SC04804-overproducing strain (MG66) induced after 24 hours of growth with $10 \mu \mathrm{g} / \mathrm{ml}$ thiostrepton for 30 minutes and 60 minutes and/or cultured for 24 hours in the presence of the inducer. The data were compared to the non-induced control and WT-lux strain (MG03) grown for 24 hours in 79 medium.

\section{Supplementary Files}

This is a list of supplementary files associated with this preprint. Click to download.

- GongerowskaJacFig.S1.pdf

- GongerowskaJacFig.S2.pdf

- GongerowskaJacFig.S3.pdf

- GongerowskaJacFig.S4.pdf

- GongerowskaJacFig.S5.pdf

- GongerowskaJacFig.S6.pdf

- Additionalfile1.docx 